of over 20 observations on each of these patients. In the table of aortic cases there is evidence to show this absence of relation, and evidence showing the presence of a relation between arterio-sclerosis and the height of the secondary wave. The patient whose tracing is shown in Fig. 11 suffered from chronic emphysema and presented little arterio-sclerosis. The subject of the tracing in Fig. 12 had marked sclerosis. The want of relation between arterial disease and high blood pressure has already been referred to. The general fall of the writing style from the apex of the pulse curve depends on two factors-the condition of the arterial wall and the rate of outflow. The two

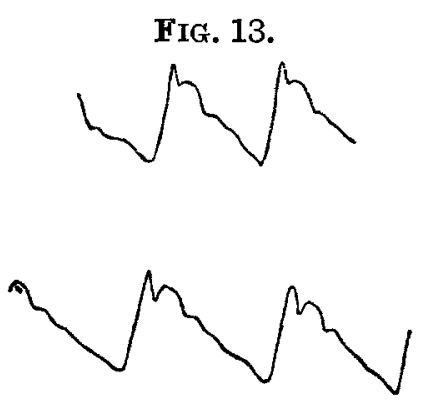

tracings shown in Fig. 13 were taken from cases of generalised arterio-sclerosis, the first with a blood pressure of 130 millimetres, the second associated with granular kidney and a pressure of 250 millimetres-yet the two tracings are practically identical.

Bibliography.-Wa. Broadbent: Brit. Med. Jour., Jan., 1899, vol. i., p. 75. Broadbent: The Pulse, London, 1890. Chapman : cited by Allbutt, A System of Medicine, London, 1898. Corrigan : Edinburgh Medical Journal, 1832. Galabin: Transactions of the Royal Medical and Chirurgical Society, vol. lix., 1876, p. 361. Janeway: The Clinical Study of Blood Pressure, New York and London, 1904. Keyt : Sphygmography and Cardiography, New York and London, 1887. Landois and Stirling. Text-book of Physiology, 1888 Marey. La Circulation du Sang din 7274. 189-74; Guy's Hospital Reports, 1879. Morison : THE LANCET, Dec. 29th, 1894, p. 1532. Sanderson : Handbook of the Sphymograph, London. 1867 Sansom : The Diagnosis and Diseases of the Heart, London, 1892. Steell Syphgmograph in Clinical Medicine, London, 1899; THE LANCEN (1) 24 , jo94, p. 1206 .

Taff's Well, Cardiff.

\section{THE RASH IN CEREBRO-SPINAL MENINGITIS.}

By WILliaM WRIGHT, M.D.GlasG., D.P.H.CaNtaB., SENIOR ASSISTANT MEDICAL OFFICER OF HEALTH, GLASGOW.

IN only a few of the numerous cases of the above disease which have occurred in Glasgow since the first quarter of the year has a rash appeared. This is in accordance with the reports of similar epidemics from various quarters in Britain. Herpes has been noticed in several and is usually situated at the angles of the mouth. But it is in regard to those cases in which a definite rash has appeared on the body before death that I desire to call attention. In two a decided purpuric rash, purple in colour and hæmorrhagic in character as spots, with well-demarcated edges, varying in size from a pin head to rather smaller than a lentil, were seen closely packed on the dorsum of the feet and nowhere else on the body. In another in which death took place within 16 hours from the time of onset (the first symptom being that of delirium, the child waking at $4 \mathrm{~A} . \mathrm{M}$. in this condition) a well-marked punctate hæmorrhagic rash, each spot singly of the size of a pin head, and in places in clusters of six or seven, was seen scattered all over the trunk and limbs. In another in which death took place after 24 days' illness a rash appeared on the seventh day and from the subsequent history evidently came in crops. On examination on the twenty-first day of the illness, purple and maroon spots, circular, with regular edges all the same size-i.e., that of a lentil-were seen on the dorsum of the feet, on the arms, the legs, the trunk (back and front), four below the chin, and one behind each ear. They were scattered over the body with areas of three to four inches of normal skin between each. These spots were definitely hæmorrhagic in character and so well defined as to be seen from a considerable distance, the picture presenting quite the aspect of "spotted fever." A cluster of 15 maroon spots occupied the interscapular space and appeared on the previous day. On visiting the case the following day those spots previously maroon had changed to purple, were still of the same size, circular with regular edges, but now quite purple. Next day-i.e., the twenty-third day of the illnessthey had almost disappeared and fresh maroon ones were seen in other situations. Larger pale-blue blotches with irregular edges fading into the surrounding tissues, 16 in number, were also noticed on the trunk and limbs. They occupied the cutis vera, normal skin could be seen distinctly over them, and at no time was any alteration in their colour, appearance, or position noted. Glasgow.

\section{A NEW METHOD OF ADMINISTERING AN AN ÆSTHETIC THROUGH A TRACHEOTOMY TUBE.}

BY WALTER P. COCKLE, M.D. DuB.,

AN.ASTHETIST TO THE METROPOLITAN EAR, NOSE, AND THROAT HOSPITAL.

THose of us who are called upon to administer an anæsthetic to a patient through a tracheotomy tube, whether the operation be for laryngotomy, thyrotomy, or other operation requiring a preliminary tracheotomy, have usually adopted one or other of the following methods-namely, a small catheter attached to a Junker's apparatus, a flexible tube and funnel (Hahn's), or a Skinner's mask held over the tracheotomy tube at a suitable distance. The objection to the first two methods is that they tend more or less to obstruct the already diminished air-way, which is one of the great difficulties in the way of administering an anæsthetic in these cases. The presence of a tracheotomy tube in the trachea is already a narrowing of the passage; if anything further, as a catheter, be introduced into this it means a further narrowing; or should respiration be carried on through a long tube the case is even worse-and add to this the deleterious effect of chloroform on respiration and the danger to the patient becomes enormously increased. With regard to the Skinner's mask, the size of the thing itself and the hand of the anæsthetist, taken in conjunction with the smallness of the field for operation, must hamper the movements of the surgeon considerably. Even in the Trendelenburg position the gain in room is not sufficient entirely to counteract these objections. With respect to charging up a patient with chloroform in these cases, to my mind it is a practice to be condemned as fraught with much danger; besides, the patient keeps coming round, often at inconvenient times for the surgeon. With a view to overcoming these difficulties I have had an instrument made for me by Messrs. Hockin, Wilson, and Co. The total length of the instrument is about 15 inches and it is composed of a handle, $F \mathrm{G}$, and a long arm, FEDCB to $A$. The latter is of flexible

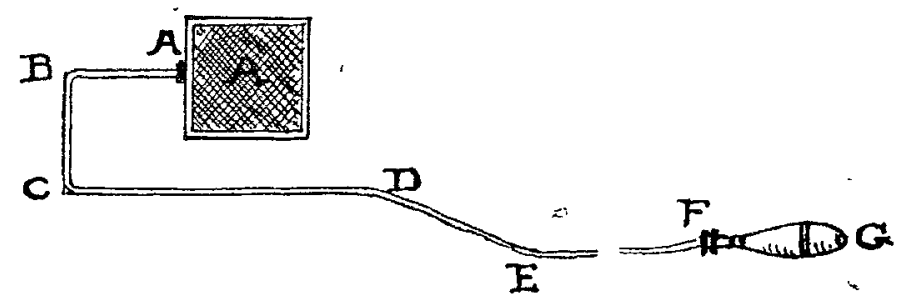

Diagram of Inhaler.

metal from $D$ to $A$ and is bent as illustrated. $A$ is a one and a half inches square frame, which is to be covered with lint held in position by a safety-pin or stitching.

To use the instrument a piece of lint or similar material is stretched across the square $A$ so as to coper it above and below and held in place by means of a safety-pin. Chloroform or C.E. is sprinkled on this from a drop-bottle and the part $B C$ is rested on the sternum of the patient, so that $\mathrm{A}$ is above the tracheotomy tube. The limb $\mathrm{C} D$ to $E$ is so bent as to bring the point $E$ well down towards the operation table out of the way of the surgeon; E F gradually sloping up and bringing $G$ to about the level of the patient's ear. The length of the instrument enables the anæsthetist to stand well back while using it. The square A 
can be raised or lowered over the tracheal opening in two ways-first, as the metal at $B$ is flexible it should be bent up to an angle of about $30^{\circ}$; and secondly, using $\mathrm{C} B$ resting on the sternum as a fulcrum by merely raising or lowering the handle $\mathrm{F} G$ the distance of $\mathrm{A}$ above the tracheotomy tube can be easily adjusted from time to time, to whatever extent desired, according as less or more chloroform is to be given.

In order to replenish the anæsthetic it can either be sprinkled on the lint while in situ from a drop-bottle or the whole instrument can be withdrawn sideways for the purpose without trouble. The double lint on the square frame takes a good charge of the anæsthetic and being donble and sloping downwards towards the sternum the liquid does not tend to drop on to the tracheal opening should too much accidentally run out. By this method the air-way is not encumbered and feathers can be passed into the tube at any time.

I will quote a case in which I used a model of this instrument and where, I am sure, the patient could never have stood a catheter or tube introduced into the tracheal opening.

The patient, a boy, aged two and a half years, had total occlusion of the larynx due to papillomata, and was sent to hospital for operation. A tracheotomy had been performed some time previously, and through this opening the child breathed fairly well, but the pulse intermitted about every third beat. I anæsthetised the patient with chloroform in the first instance-he appeared to take it well. However, just before the operation was begun the breathing became bad, so I changed to ether, and as it improved to C.E., gradually increasing chloroform until finally anæsthesia was maintained by chloroform alone-using the same instrument throughout. The first incision was made during the C.E. administration and the operation was proceeded with. It was curious to note how as the patient took more and more of the anæsthetic he became inured to it, for after half an hour he took pure chloroform without any unfavourable effect whatever either on respiration or the heart he breathed freely, kept quite warm, and the face was a good colour all the time. Altogether he was under the anæsthetic three and a quarter hours, six drachms of chloroform being used and about three ounces of ether. There was no interruption of any kind during the operation. By adopting this method the patient had the full benefit of the calibre of the tracheotomy tube as a medium for respiration. There was no resistance to expiration; the miniature mask is not cup-shaped but perfectly flat and was never nearer to the tracheal opening when charged with chloroform than about one and a half inches, thus allowing a good outlet during expiration-which is, I think, of more importance than is generally supposed-as well as allowing a desirable proportion of air to mix with the anæsthetic prior to inhalation.

Should the operator and his assistants desire to take full possession of the head and neck of the patient and the anæsthetist, having put the patient under, be required for this purpose to continue the anæsthetic from the other end of the couch, this can be easily accomplished by inverting the instrument and extending the frams carrying the lint about $150^{\circ}$. By this means, and still resting B $\mathrm{C}-$ which for simplicity I may call the cross-bar or sternum piece of the instrument-on the sternum, the whole can be manipulated in precisely the same manner as before-that is to say, by raising or lowering the handle the mask is lowered or raised at will. In the case I have just quoted it was not necessary to adopt this course, as when the surgeon wanted to work from above or to obtain a good view downwards from the head to the larynx it was possible for him to obtain his wishes during a brief interval in which the anæsthetic was suspended.

One word of warning is perhaps necessary in the use of this instrument, and it is that while the surgeon is engrossed in his work he may inadvertently rest his arm on the lintcovered frame and press it down over the tracheotomy tube, but this can easily be guarded against by observing when he is going to adopt that position and moving the instrument out of his way for the time.

The advantages to be derived from this method may be summarised as follows: (1) It administers chloroform or C.E. efficiently ; (2) practically it does not interfere with the surgeon at all; (3) it gives the surgeon the maximum space possible; (4) it is much safer than a tube and funnel or catheter and Junker arrangement, and it is not so cumbersome and obtrusive as a Skinner's mask; (5) it is cheap durable, and easily sterilised; (6) it is flexible and can be accommodated to any position to regulate the quantity of anæsthetic given; (7) in case of necessity it will administer ether alone as a stimulant; and (8) it can be used from any: position to suit the surgeon.

Ealing. W.

\section{ANKYLOSTOME PARASITISM AMONG THE NATIVE LABOURERS IN THE TRANSVAAL.}

By W. G. TOTTENHAM POSNETT, F.R.C.S. IREL., HONORARY PATHOLOGIST TO THE JOHANNESBURG HOSPITAL.

WHILE acting as medical officer in charge of the Johannesburg Prison from March to August, 1904, I noticed that many of the natives under my care were suffering from anæmia, some to a slight degree, others showing marked blanching of the mucous membranes, though, like all natives, they did not report themselves sick until they were in a serious condition. One morning the head warder in charge of the native section of the gaol sent a "boy" up to the hospital as he seemed ill, and on my rounds I saw him and made the following note of his condition. He was a tall well-nourished "boy" (Shangaan). The mucous membranes were almost white, the respirations (while standing) were 29 , the temperature was $97 \cdot 4^{\circ} \mathrm{F}$., and the pulse was 112 . There was great cardiac distress, with diffuse pi æcordial pulsation. When asked where he was sick he pointed to his epigastrium. Suspecting ankylostomiasis, though never having heard that the disease occurred among the natives here, I examined a portion of his stool microscopically and found numerous eggs of the ankylostomum duodenale. Being very busy at the time I was unable to investigate the case further but the "boy" got quite well under the usual thymol treatment.

Since being appointed honorary pathologist on the staff of the Johannesburg Hospital I have had more opportunities of following up the idea that I had formed that the natives were extensively infected with ankylostomes. This surmise has been borne out by the investigation of some 40 specimens of the stools of natives admitted for various diseases to the native medical ward of the hospital. The "boys" from whom the specimens were obtained belong to the many and various tribes which inhabit South Africa, south of Rhodesia, and including Portuguese East Africa. Out of the 40 specimens of fæces subjected to microscopical observation 32 per cent. contained the ova of the ankylostome None of these natives showed symptoms of ankylostomiasis. I noticed that the natives from Portuguese East Africa and the Shangaans from the low veldt were more frequently the hosts of the parasite than the members of other tribes. This parasite is therefore evidently widely distributed throughout the natives employed on the mines of the Witwatersrand and such being the case the economic importance of its recognition to the mining community of these fields cannot be passed over in a light manner. Although not as a rule, so far as I can find out, a direct cause of death among the natives of the mines its debilitating presence must be counted as a serious factor in the high death rate prevailing among our native labourers. But the importance of this parasitic nematode worm being a very frequent inhabitant of the intestines of our coloured workmen does not end with the native-we have to think of our white miners as well.

From information imparted by old miners on the Rand it is evident that the sanitary conditions underground on the mines during the time of the South African Republic were in a most primitive condition, consequently the native evacuated his intestinal contents anywhere and everywhere in the workings, thus contaminating the ground with a most dangerously infective host of ova of the ankylostome. The white miner was far from innocent in the same respect. It is therefore a foregone conclusion that our white miners must be extensively infected by ankylostome parasites, and, although they may not show any symptoms of doing so, their working capacity and illness-resisting powers must be considerably reduced. Unfortunately, I am not in a position to be able to obtain the necessary material for a microscopical search of the white miners' intestinal parasites so as to prove the above assumption, but I do not doubt its correctness. In 1902 Haldane and Boycott were sent to investigate miners' 